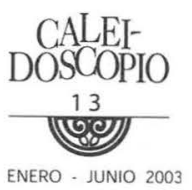

\title{
LA HERMENÉUTICA ANALÓGICA: RETOS Y APLICACIONES
}

MAURICIO BEUCHOT

Instituto de Investigaciones Filológicas, UNAM

EnRIQUe LuIÁn (comp.), Hermenéutica analógica: una propuesta contemporánea.

Diálogos con Mauricio Beuchot, Universidad Autónoma de Aguascalientes, Aguascalientes, 2002, $125 \mathrm{pp}$.

En este libro, compilado cuidadosamente por Enrique Luján, se recogen varios trabajos de profesores de la Universidad Autónoma de Aguascalientes. El tema en torno al cual giran es el de la hermenéutica analógica, método interpretativo que trata de evitar la univocidad y la equivocidad. Lơ unívoco es lo claro y lo distinto, es la interpretación totalmente literal y perfecta, la cual es inalcanzable y no pasa de ser un ideal; pero muchos, desengañados al tratar de alcanzar esta aproximación, se han abandonado al juego de la interpretación equívoca, que es totalmente subjetiva, relativista y hasta caótica la mayoría de las veces. Por eso hacía falta una hermenéutica analógica, que fuera intermedia entre las dos anteriores; pero no como algo trivial y simplista, para lo cual sirve ese concepto de la analogía, tan trabajado por los griegos, desde los pitagóricos, pasando por Platón, hasta Aristóteles. Es un concepto muy elaborado, nada simple y que exige mucha sutileza, en la línea de lo que el Estagirita llamaba la phrónesis, la cual es la prudencia, y es lo que en la actualidad Gadamer puso como instrumento para interpretar. 
Pues bien, los trabajos compilados son muy interesantes en diferentes aspectos. Después de una introducción muy ilustrativa realizada por el compilador, aparece, en primer lugar, una aplicación muy lúcida que hace Jorge Ávila Storer de la hermenéutica analógica a la crítica literaria, analizando con esta herramienta conceptual el célebre y hermoso cuento de Borges intitulado "El Aleph". Allí nos hace ver que la filosofía de Borges es nominalista $y$, en este sentido, equivocista, pues nos deja sin entender por qué los instantes se conectan unos con otros, formando esa línea infinita que es el tiempo.

Todo parece reposar en la fragmentación, no en estructuras precisas, lo cual lo pondría en su antípoda, el platonismo. La explicación del autor llega a producir un cierto escalofrío, ya que nos muestra un Borges para el que no tienen ningún sentido los instantes pretéritos y, por lo mismo, tampoco el presente ni los futuros. Así, la analogía le sirve a Ávila para señalar que la salida de Borges es la imaginación: imaginar un infinito de instantes, una eternidad como ideal, aunque muy poco alcanzable. Y señala esto como una característica del desencanto que sufren los intelectuales del cono sur de nuestro continente.

Viene en seguida el ensayo de Jorge Alfonso Chávez Gallo, quien parte de los cuestionamientos que dejó Nietzsche para toda hermenéutica futura. Es cierto, que al abolir el "mundo verdadero", este pensador abolió también el "mundo de las apariencias"; sólo dejó la interpretación. Esto se conecta con otra cosa que dijo el filósofo, de manera tan lapidaria y tajante, que ha sido objeto de las más encontradas interpretaciones: "No hay hechos, sólo interpretaciones". Del texto de Chávez Gallo se deduce una interpretación que a mí me complace, precisamente por estar en la línea de la hermenéutica analógica. Ese aforismo no significa que sólo hay interpretaciones sin hechos, así como no hay hechos sin interpretaciones; lo que hay son hechos interpretados, esto es, ni hechos puros sin interpretaciones, como querían los positivistas, ni interpretaciones puras sin hechos, como querían los románticos. Se trata de llegar a una mediación, a una interpretación proporcional, en la que se dice que ni una cosa ni otra, sino algo de las dos, dialécticamente sintetizadas, y ésa es una interpretación auténti- 
camente analógica, como la que hace este autor.

Luego, José de Lira aborda el tema de la ciencia. En ella cada vez está teniendo más cabida la hermenéutica, sobre todo por obra de Karl Popper, a quien usa para contrastarlo con los positivistas del Círculo de Viena. También el autor utiliza a Von Wright, quien traza una distinción útil entre la tradición aristotélica y la tradición galileana. Esta última es la que ha dado origen al. positivismo, con su empirismo y cientificismo; pero la otra, la tradición aristotélica ha engendrado lo que Von Wright llama, de manera muy general, corriente hermenéutica, que viene a ser antipositivista. El autor nos hace ver con claridad y buena argumentación, que Popper, dentro de su antipositivismo, propulsó la hermenéutica, para que tuviera cabida en la más reciente filosofía de la ciencia.

Por su parte, Juan José Láriz Durón se centra en la ética, que es suprincipal preocupación, y allí hace aplicaciones de la herme néutica analógica. Aunque Gadamer rehuyó la parte política y aún normativa en la hermenéutica, sin embargo, siempre aceptó su relación con la ética. Y es también aquí donde resulta útil Aristóteles, pues su ética de las virtudes, entre las que descuella la phrónesis, nos ayuda a vincular la conducta moral con la analogía o proporción. El autor también aprovecha a Ricoeur y a Lévinas para ver la injerencia de la ética en la hermenéutica. Y en la línea de la hermenéutica analógica, nos habla de una ética hermenéutica, y además proporcionada o que realiza un equilibrio difícil, pero que es lo único que nos puede dar una ética que se libre del absolutismo y del relativismo.

Asimismo, Enrique Luján hace una detallada exposición de la hermenéutica analógica, señalando muy bien los problemas que trata de resolver. Esto es importante, porque, al exponer una teoría, se corre el riesgo de comprenderla en su estructura sistemática, pero sin saber qué problema trata de responder. Vemos la solución, pero no el problema. Y ese problema no puede ser otro que el de la validez de la interpretación. El autor hace ver, desde la historia misma de la hermenéutica, y llegando hasta Heidegger y Gadamer, la necesidad de instaurar una hermenéutica analógica. Lo señala bien: la analogía es la que puede dar límites a la interpretación, la cual 
corre siempre el peligro de irse al infinito y no tener término, pero tampoco sentido. Eso sería quedarnos en realidad sin hermenéutica. Por esto, según lo manifiesta el autor, una hermenéutica analógica sería una respuesta a esa pregunta que Umberto Eco puso como título de uno de sus libros: Los límites de la interpretación.

Toca el turno a Caleb Olvera, quien señala que en la mayoría de los filósofos serios no hay una postura depurada o absolutista. Por ejemplo, Quine sería más que univocista, un pensador unívocamente análogo o análogamente unívoco, al igual que Derrida, estaría en una postura analógica pero más inclinada a la equivocidad. En verdad me parece muy sensata esta cautela en la historiografía de la filosofía, la cual constituye una verdadera hermenéutica y, concretamente, una faceta de la hermenéutica analógica. De esta manera nos obligaremos a matizar más nuestras aseveraciones acerca de los filósofos clásicos que frecuentemente exponemos, pues no hay tipos puros, sino mediados unos con otros.

De manera muy perceptiva, Patricia Patiño Bahena apunta a algunas virtudes que ve en la hermenéutica analógica. Después de trazar las configuraciones principales de la hermenéutica y de enlistar las dificultades más acuciantes de la misma, por ejemplo, el de la verdad en la interpretación, expone muy bien lo que intenta conseguir la hermenéutica analógica, a saber, un punto móvil prudencial o virtuoso. Pero, como los virtuosos en la música, no se trata de un punto fijo, sino que exige un gran dinamismo y trabajo realizable por la concentración del intérprete y por su destreza o sutileza.

En seguida viene el trabajo de José Guadalupe Rodríguez Martínez, en el que se ponen los dos aspectos que pueden caber a la hermenéutica, el de la purificación del sentido y la del mutuo entendimiento. Es lo que antes hacía la retórica clásica, que era vista por los antiguos como ahora vemos a la hermenéutica, como una teoría de la comunicación. El autor nos hace ver que la hermenéutica tiene que servir para leer y para expresar, para decodificar y para encodificar, y esto tiene que hacerlo la hermenéutica analógica de un modo singularmente cuidadoso, pues la analogía está como intermedia entre la identidad y la diferencia. No puede quedarse en ninguna de 
ellas, tiene que conjuntarlas, aunque, a la postre, alguna de ellas ha de predominar, a saber, la diferencia, pero nunca sacrificando a la otra, esto es, a la identidad.

El trabajo final es el que pertenece a Marco Antonio Venegas Medrano. En él se ubica a la hermenéutica analógica como proyecto de autoconciencia. Con varios señalamientos críticos, nos hace tener advertencia de que es difícil, sino imposible hacer que los demás lleguen a esa autoconciencia analógica. Lo que dice el autor es cierto y nos ayuda a no abrigar esperanzas inalcanzables. Ya será mucho con que logremos concientizar a algunos cuantos.

Así, el libro que presentamos es un texto excelente, de crítica positiva y constructiva, que ayuda a seguir adelante en el camino de esa hermenéutica analógica que apenas va, trabajosa pero confiadamente, construyéndose poco a poco. 
